\title{
Exports and Wages: Discriminating between the Sources of Rents
}

\author{
Lionel Fontagné \\ CEPII (Paris, France) \\ PSE (University Paris 1-CNRS) \\ Daniel Mirza ${ }^{* *}$ \\ CREM (University of Rennes 1-CNRS), \\ CEPII (Paris, France)
}

\section{Introduction}

When do exports lead to rents? And when are they shared with employees? The literature that studies the relationship between trade openness and wage premiums in models of rent sharing, does not emphasize enough the conditions under which rents are obtained '. Rents are not always acquired from selling to a given market especially if the latter exhibits high competition.

Besides, the literature does not usually distinguish among the destinations that are the most profitable to employers and employees. This paper proposes a double test that tries to handle these issues.

Most empirical work studies a relationship between wage premiums and profits, where openness is considered as a shock. As profit measures are not accurately observed, and because they might be endogenous to wages, most authors instrument them with some trade related variables, mainly price vectors (Abowd and Lemicux Abolem (1993), Abowd and Allain (1996) or more recently Dobbelaere and Brock (2006) provide examples). The mechanism they actually rely on is best illustrated in Borjas and Ramey (1995).

\footnotetext{
We are grateful to Rod Falvey, Sebastien Jean, David Margolis for very helpful comments on an earlier draft of the work.

“ Corresponding author. email: daniel.mirza@univ-rennes1.fr

1 Budd and Slaughter (2004) or Budd, Konings and Slaughter (2005)
} 
Openness, by increasing the number of firms in the marketplace, should shift rents from national to forcign firms, which in a model of rent sharing reduces domestic employees' wages.

In this paper however; openness is not considered as a shock. Our setup departs from a Cournot game between firms, domestic and forcign, where unions and employers choose together wages and output served to each market, in an efficient bargaining process. Firm exports, prices and market shares are the outcomes. Inferred profits are then distributed among employers and employees via higher wage premiums. From this set-up that generalises that of Sen and Dutt (1995) to open markets, we derive in this paper a theoretical relation linking wage premiums to both domestic and foreign market shares, without any need of profits or quasi-rents variables. We demonstrate that this firm level relation could be formally aggregated to an industry level one to be directly tested.

Market shares are shown to be linked to wage premiums by a precise channel of adjustment that holds only when unions are strong and when markets are profitable for exporting firms. Now, if either firms or unions lack market power on the commodity and the labor markets respectively, then the channel between openness and the wage premium breaks down. We test the existence of such a channel between wages and market shares at the industry level for OECD countries selling on their markets as well as developing countries' markets.

But more interestingly, as firms in each sector sell to many markets, this relation cnables to discriminate further between the sources of acquired rents. Hence, we ask whether rents are the result of selling to the domestic market or whether they are due to exporting towards developed and/or developing countries' markets.

We use two UNIDO databases: the 3-digit ISIC Industrial Statistics database, as well as the Industrial Demand-Supply Balance database at the 4-digit level ISIC Code. From these sources, we construct a dataset that matches trade, activity and labor related data for around 26 industries at the 3 ISIC nomenclature (Rev.2) in 19 OECD countries, within the 19811997 period. Three destination markets are observed for each country in each industry: the domestic market, the rest of the OECD market and the developing countries' market. As the only data we have access to is at the industry not the firm level, and as we know that most of the literature use instead firm/employee level characteristics, we undertake some further tests of robustness and check ups to support the fact that our industry-level results are consistent with rent sharing theories.

We find that an increase in market shares in at lcast one of the destination markets is associated with an increase in wage premiums, in nearly four fifth of the industries. This indicates that in a high majority of the OECD industries, rents exist and unions are strong enough to shift part of 
them from wherever they are extracted. We also find however, that those rents that are shared are acquired more from selling to the OECD foreign markets than from sales to the domestic market. Finally, only a small fraction of the OECD industries benefit from selling to developing markets.

In the next section, we present the theoretical model. In section 3 we design a strategy to match theory with the data. Section 4 describes the discriminating to test to perform and section 5 shows the econometric results. Section 6 assesses the relevance of our empirical evidence by drawing a comparison with prior studies. Section 7 concludes.

\section{The analytical framework}

We begin by following an hypothesis from Sen and Dutt (1995) by considering a firm $n$ from a country $d$, acting in oligopoly à la Cournot, where employers and unions bargain simultaneously over both wages and output. This set up is a particular type of strongly efficient bargaining models, where output replaces employment in the bargaining process ${ }^{2}$. One can actually think; however, that from the unions' point of view, the variable behind output is actually employment as they know that these two variables are directly linked in production functions. For ease of exposition, we assume that output equals labor demand $y_{n}=l_{n}$. The reason for which employecs are interested in wages as much as output (or employment), and set together with their employers these two variables, is due to the fact that by bargaining solely over wages they can hurt the competitiveness of the firm in return, and thus their employment. So they moderate their wages by choosing the optimal wage and sales (or exports to each of the markets in our model) that maximize the combined welfare of both employers and employees.

Here, we simply add to the Sen and Dutt framework the hypothesis that the firm serves its own market $d$ and exports to a foreign market $f$ (i.e: $\left.y_{n}=x_{d, n}+x_{f, n}\right)$. These markets are assumed to be segmented so that firm sales to a given market depend only on that market's characteristics (see Brander and Krugman (1983)). Pure Cournot competition between firms is

2 The concept of strongly efficient bargaining (i.e. both parties negotiate over wages and employment) has been introduced by Brown and Ashenfelter (1986). It is usually opposed to the right to manage hypothesis (i.e. unions and employers bargain only over wages only) or the monopoly union model (i.e. unions choose solely the wage rate). Then, in these models, employers settle a level of employment conditional to the wage rate accordingly determined. While Brown and Ashenfelter (1986), Card (1990) and Hosken and Margolis (1997) find a mixed support to the hypothesis of efficient bargaining. Abowd (1989) and Christofides and Oswald (1991) support completely that hypothesis. Furthermore, using data on New York State public schools Hosken and Margolis (1997) reject systematically the hypothesis that teachers' unions and school districts engage in monopoly union or right to manage style bargaining. In this article we maintain the hypothesis of strongly efficient bargaining agreements and discuss in later sections the implication of a right to manage or monopoly union assumptions on the parameters to estimate. 
considered. In appendix B, we extend the framework to $J$ markets and show that we still obtain the same type of theoretical relations to estimate.

The Nash solution to the bargaining problem would be to choose simultaneously wages, exports and domestic sales. Hence, the objective function to maximize is

$$
\left(l_{n}\left[w_{n}-w_{n}\right]\right)_{d}^{\lambda_{d}}\left[p_{d} x_{d, n}+p_{f} x_{f, n}-w_{n} l_{n}\right]^{1-\lambda_{d}}
$$

where $w_{u}$ designates the alternative wage and $\lambda$ indicates the union's degree of market power $(0 \leq \lambda \leq 1)$ in the economy $d . p_{j, n}$ and $x_{j, n}$ represent the price and the quantities sold by the firm on each market $j, \forall j \in\{d, f\}$ while $l_{n}$ stands for labor demand of the representative firm.

From the first order conditions, by deriving with respect to $w_{n}$ we obtain the following wage equation:

$$
w_{n}=l_{d}\left(\frac{p_{d} x_{d, n}+p_{f} x_{f, n}-w_{u} l_{n}}{l_{n}}\right)+w_{u}
$$

Here, firm wages are linear functions of alternative wages and quasi rents per worker (Abowd 1989). However, as markets are assumed to be segmented, then total revenues are the sum of revenues obtained from each market.

Besides, deriving with respect to $x_{j, n}$ and replacing $w_{n}$ by its corresponding function 2, we find the following quasi mark-up equation on each market $j$ :

$$
\frac{p_{d}-w_{u}}{p_{d}}=\frac{1}{s_{d}} s_{d, n}
$$

and

$$
\frac{p_{f}-w_{u}}{p_{f}}=\frac{1}{s_{f}} s_{f, n}
$$

Unlike traditional mark-ups that express total profits per unit value, quasi mark-ups stand for the total quasi rents per unit value. Equations 3 and 4 are closely related to Structure-Performance type expressions in industrial cconomics, since 'quasi' mark-ups depend on price-elasticity of demand $\sigma_{j}$ and the market share $s_{j, n}=x_{j, n} / X_{{ }_{j}}$ (i.e. $X_{{ }_{j}}$ represents total sales in market $j, j \in\{d, \Omega\})$.

Note $b_{d t}=\frac{l_{d}}{s_{d}}$ and $b_{d f}=\frac{l_{d}}{s_{f}}$. Moreover, let $p_{n} y_{n}=p_{d} x_{d, n}+p_{f} x_{f, n}$ be the total revenue for firm $n$ where $p_{n}$ is a producer price index function of prices set in the domestic and foreign markets. Let also $e_{d, n}$ and $e_{f, n}$ be respectively the sale rate to the domestic market and export rate to the forcign one (i.e. $\left.e_{j n}=\left(\frac{p_{j} x_{j, n}}{p_{n} y_{n}}\right), \forall j \in\{d, n\}\right)$. Replacing equations 3 and 4 in 2 , we end up with the following real wage function: 


$$
\frac{w_{n}}{p_{n}}=b_{d d} e_{d, n} s_{d, n}+b_{d f} e_{f, n} s_{f, n}+\frac{w_{u}}{p_{n}}
$$

Hence, the real wage equation, net from the real alternative wage, is a linear combination of the weighted export market share and the domestic share. The intuition behind this relation is that an increase in the market share in a given market $j(\forall j \in\{d, f\})$, translates into more quasi rents for the firm, that are shared with the employees in the presence of some union power. Now, these quasi rents, and thus wage compensation gains, are the more important the more the fraction of output used to serve this market j (i.c. $e_{j, n}$ ) is high.

Thanks to the assumption of efficient contracts, and if one has to solve completely the model, weighted market shares do not depend in return on observed wages in the industry. They are actually a function of alternative wages. To see this, consider equation 3 related to market $d$. For more clarity, let $w_{u}=w_{u, d}$ to be the alternative wage in the domestic country and $w_{u, f}$ that prevailing for the foreign country. When summing over all $N_{d}$ domestic sellers and $N_{f}$ forcign firms in equation 3 , and by rearranging terms, one can obtain an expression for equilibrium prices $p_{d}=\frac{s_{d}}{s N_{. d}-1}\left(N_{d} w_{u, d}+N_{f} w_{u, f}\right)$. Hence, prices depend only on alternative wages. The same kind of reasoning applies for equation 4 . From there, one can easily obtain an expression for each quantity sold by a firm on its domestic or export markets that only depends on alternative rather than industry wages. This result is not surprising and has to be compared to that obtained for the equation of labor demand with efficient bargaining in the labor theory literature. In that framework, labor demand that is a direct measure of output quantities is also affected by alternative rather than observed wages (see for instance Brown and Ashenfelter (1986)).

We do not have access to firm-level data. We present in what follows however, an aggregation strategy that enables us to test a variant of the above equation at the industry level. Actually, if we compute the real average wage at the industry level $w / p=\left[\sum_{n} w_{n} l_{n} / L\right] / p$ using equation 5, we obtain a relation to test that is rather similar to the latter, except that now export rates, domestic sale rates and market shares are not specific to a firm but to a representative industry.

To see this, let $S_{d}=X_{d} / X_{\cdot d}$ be the observed domestic market share and $S_{f}=X_{f} / X_{\text {. }}$ the market share held on the foreign market for a given industry in an observed country. Consider $E_{d}$ and $E_{f}$ to be respectively the corresponding industrial domestic sale intensity and export intensity. Let $L=\sum_{n} l_{n}$ represent total labor demand at the industry level. Morcover, 
define $\psi_{d}=\left[\Sigma_{n}\left(\frac{x_{d L_{n} n}}{X_{\cdot d}}\right)^{2}\right]$ (resp. $\psi_{f}$ ) to be a concentration index that informs about the degree of competition within all of the firms of the observed country selling to market $d$ (resp. to market $f)^{3}$. We can now derive mathematically from equation 5 , the industry relation of average wages (see appendix A for more details) :

where

$$
\frac{w}{p}=b_{d d}^{\prime} E_{d d} S_{d}+b_{d f}^{\prime} E_{f} S_{f}+\frac{w_{u t}}{p}
$$

and

$$
b_{d d}^{\prime}=\frac{\lambda_{d} \Psi_{d}}{\sigma_{d}}
$$

$$
b_{d f}^{\prime}=\frac{\lambda_{d} \Psi_{f}}{\sigma_{f}}
$$

Before interpreting the $b$ ' parameters, assume first that they are finite and positive. The wage relation we obtain at the industry level is comparable to that expressed at the firm level, except that now the right hand side variables are not specific to a firm but relative to an industry in the observed country. Besides, now that the relation is expressed at the industry level an additional term $\Psi$, relative to the state of competition within the exporters in that industry, enters the equation.

That relation between the wage premium and trade shares holds only when firms are strong enough to generate rents from selling to a given market and unions are strong enough to shift some of them back to employces. Indeed, the parameters $b^{\prime}{ }_{d d}$ and $b_{d f}$ express the interacted market powers of both unions and firms in determining industry real wages. Typically, the ratio of concentration to price elasticity $\left(\frac{\Psi_{j}}{\sigma_{j}}\right)$ form an average market power indicator for exporters to $j, \forall j \in\{d, f\}$. Hence, the larger the market power in the destination market, the larger the rents to be potentially shared. Whether or not these rents are actually shared between workers or cmployers, depends then on the bargaining power of unions captured through $\lambda$.

\section{$3 \quad$ Matching of data and theory}

The 3-Digits Industrial Statistics Database (Indstat3) reports data on activity such as 3-digit industry total compensation (wages and benefits), em-

3 See appendix for more details. 
ployment and production (ISIC rev.2). UNIDO provides trade data with Developed and Developing countries (imports and exports) at the 4-digit industry level (ISIC rev.2 as well), easily aggregated to 3-digit. Then, by matching these two databases, we were able to construct a table of activity and trade data for 19 developed countries in 26 industries between 1981-1997. We present in table 1 the number of industries where data is available in each country over the period 1981-1997.

It is to be noted that UNIDO trade data are based on the United Nations Commodity Trade tapes and thus, are expected to be exhaustive by country and industry while UN-Indstat3 database reports activity data from different sources of information. A significant proportion of this data appears to be collected from business surveys conducted by UNIDO, which suggests that wages, employment and production could be underestimated relative to their real values in national statistics. However, total compensation in the theoretical model to be tested is expressed relative to employment, and thus the related variable $w_{i}$ constructed from UNIDO would be a good proxy of the real one.

More problematic is the production variable which is used to compute domestic and foreign market shares. However, we compared production data from the STAN-OECD database based on national accounts ${ }^{4}$ to that of UNIDO and found values that were rather similar.

The relation to be tested needs price levels $(p)$ at the denominator of the variables of industry and alternative wages, otherwise the parameter values (in the numerator) would be significantly overestimated. We thus approximate a vector of prices in a market by a vector of weighted mean wages, across domestic and foreign countries selling to that market ${ }^{5}$. We note these prices $\tilde{p}$.

Besides, the alternative wage in the considered industry is not directly observable from the data. One way to model the alternative wage that is specific to a representative industry in a country is to consider that its deviation from the mean national wage could be captured through a deviation of productivity from its mean $\left[w_{u}-\bar{w}\right]=\beta_{p t y}[P t y-\overline{P t y}]$. Here though, we have chosen a more gencral expression where:

$$
w_{u}=\beta_{w} \bar{w}+\beta_{p r y}[P t y-\overline{P t y}]
$$

4 More rigorously, the OECD production data are estimated values from both surveys and national accounts series.

5 Obviously, this variable is more a mean cost than a price proxy. This underestimation of real prices (at the denominator) would still lead to an overestimation of the parameters but to a much lesser extent. Indeed, following Oliveira-Martins et al (1996) and Schmalensee (1989) among others, prices are shown to be only $20-30 \%$ higher than costs on average. 


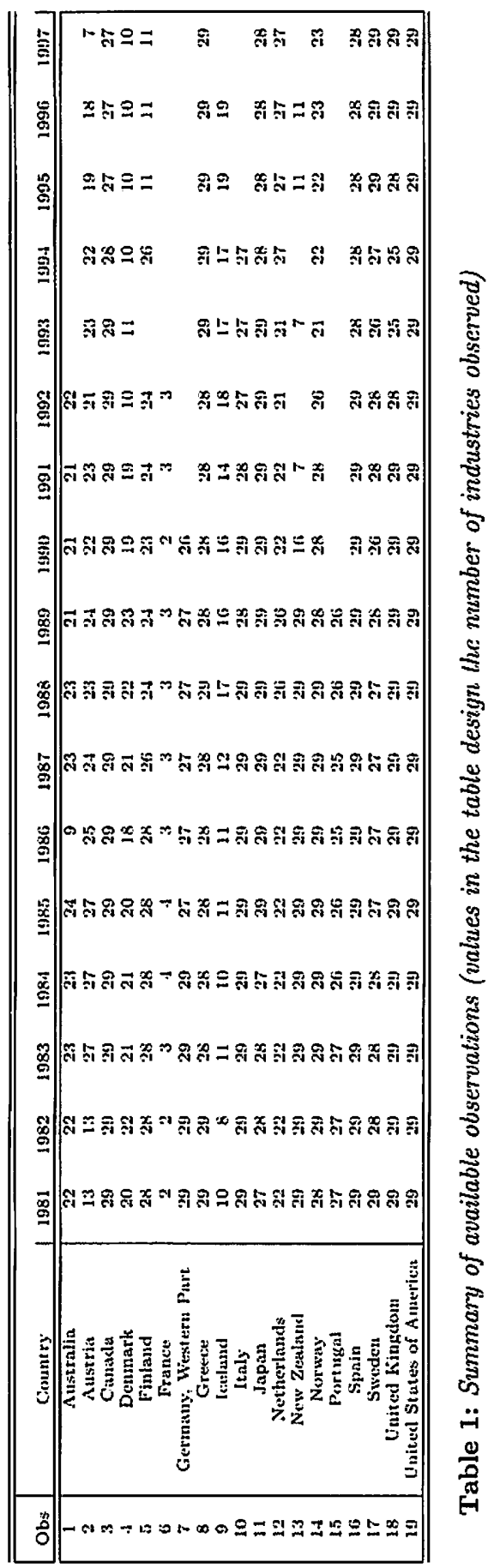


Pty is labor productivity (production per employec) observed in the industry while $\bar{w}$ and $\overline{p t y}$ represent respectively national average wages and productivity.

Further, the theory we develop in section 2 is based on a homogeneous product framework sold in well defined marketplaces (i.c. domestic or foreign markets). UNIDO data does not fit directly in that framework as it relies on rather aggregate classifications, both in terms of the reported industries and market boundaries.

More precisely, the data is observed at the 3-digit level (ISIC classification) and three group of destination markets can be distinguished: the domestic market $d$, the Industrialized countries' market ( $f=I n d$, hereafter) and the Developing countries' one ( $f=D e v$, hereafter). Our theory extends very simply from a two to a three markets' framework (see appendix B). Still, each industry observed describes a group of products and each market destination observed is related to a group of countries, which suggests a potential presence of product differentiation and cross-country spatial differentiation. We show in appendix $\mathrm{C}$ that our wage equation is still perfectly consistent with the existence of differentiation, except that the value of the parameters to estimate should be higher than what is predicted by equation 6 . The reason for a higher coefficient is that differentiation increases further the degree of market power for a given firm that should be then captured through the market share parameters. More on this is detailed in what follows.

\section{The test}

Hereafter, we shall add an $i$ subscript to refer to the observed exporting country and a $j$ subscript to refer to the three destination markets of exports. The latter can designates the domestic market $(j=d)$, the industrialized economies' whole market $(j=I n d)$ or it might refer to the developing economies' markets $(j=D e v)$. We also add a time subscript.

Besides, in what follows we consider the adjusted relation of wage premiums which allows for spatial and goods' differentiation (see appendix C). This is perfectly similar to equation 6 except that the value of the parameters should now differ. As a matter of fact, in a differentiation context, $\forall j \in\{d, I n d, D e v\}$ the $b^{\prime}$ parameters are replaced by $\beta$ cocfficients, the latter being defined as:

$$
\beta_{d j}=\left[\lambda_{d} \psi_{j} \frac{\kappa_{j}}{\sigma_{j}^{e}}\right]
$$


Herc, $\sigma_{j}^{*}$ stands for the mean price-elasticity of 'effective' demand (see appendix 10). In addition, an extra parameter $\kappa_{j}$, enters the definition of the coefficients. As shown in the appendix, this parameter is an increasing function of the degree of differentiation and could take on values between 1 (homogeneous goods and perfect market integration case) and $\left(\frac{X_{j}}{x_{i j, n}}\right)$, (perfect differentiation in products and space). Thus, the $(\beta)$ 's are expected to be always either null or positive, with values that could be very high in case of high spatial or goods' differentiation.

We also replace the alternative wage in equation 6 by its function (eq. 7 ) in the wage relation 6 , and the price by its proxy $\widetilde{p_{i l}}$. We then obtain the following specification to test ${ }^{6}$ :

$$
\begin{aligned}
& \frac{w_{i t}}{\widetilde{p_{i t}}}=\beta_{d, d}\left(E_{d} * S_{d}\right)_{i t}+\beta_{d, I n d}\left(E_{I n d} * S_{I n d}\right)_{i t}+\beta_{d, D e v}\left(E_{d e v} * S_{D e v}\right)_{i t} \\
& +\beta_{w} \frac{\overline{w_{i t}}}{\widetilde{p_{i t}}}+\beta_{p t y} \frac{\left[P t y_{i t}-\overline{P t y_{i t}}\right]}{\widetilde{p_{i t}}}+\varphi_{i}+\varphi_{t}+u_{i t}
\end{aligned}
$$

Equation 8 above provides a basis for a two stage discriminating test. The first stage focuses on the existence of a rent sharing channel by market. The econometric test to be undertaken is:

H0: $\beta_{d j}=0$ (i.e. no rents from a given market $j$ or no unions in $d$ ) against $\mathrm{H} 1: \beta_{d j}>0$ (i.e. positive rents from $j$ and strong unions in $d$ )

Put differently, by testing for the existence of a channel of adjustment between trade shares and wage premiums we are indirectly testing for the joint existence of strong unions on the domestic labor market and positive rents acquired from the destination product markets. When unions are weak or in the absence of rents, the channel breaks down and more market shares at home or on foreign destinations do not affect the wage premium.

Under the null however, we do not know so far whether the channel between market shares and wages breaks down because of absence of rents or because of absence of unions. There is a way however, to discriminate further between those two possibilities. If a $\beta$ parameter happens to be positive and statistically significant in at least one of the market sources for rent-sharing, then one could easily infer that unions in the exporting country do exist, otherwise that channel would not have existed. Hence, if the remaining market destinations are not increasing wage premiums, that

6 We have added country and time fixed effects in order to capture other potential components of the wage relation that are specific to country or time. The regressions are ran by industry and thus a subscript $k$ is implicit. 
would be an indication of absence of rents from selling to those destinations. Put formally, we want to run the following second test:

H0 : $\beta_{d j}=0 \mid \beta_{d j}=0$ (i.e. no rents $\forall j, j$ or no unions in $d$ ) against $\mathrm{H} 1^{\prime}: \beta_{d j}=0 \mid \beta_{d j}>0$ (i.e. no rents from $j,(j \neq j)$ although existence of unions in $d$ )

In the first hypothesis ( $\left.H 0^{\prime}\right)$, all the rent sharing channels by which wages could increase, are broken: either no rents are acquired in each of the markets j and j' or if they do, no unions exist to redistribute them over to employees. In the alternative $\left(H 1^{\prime}\right)$, there is a rent distribution channel due to acquiring market shares in $\vec{j}$, which means that unions do exist and are strong enough to reallocate rents. However, the channel related to a different market $j$ is not functioning which indicates that although unions do exist, no rents are acquired in the latter to be able to be shifted back to employees.

A final and very important observation has to be added, however. The $\beta$ parameters could be estimated to be negative. In that case our theory based on efficient bargaining and the structure performance paradigm does not hold. The negative signs could be then interpreted as a reverse causation, in which high wages lead to shrinking market shares on markets were competition is tight.

There could be another source of bias however, that is not due to the hypothesis underlying the relation to test but that is due to some measurement errors in the data at hand. In case the alternative wage is not well captured by its proxies, and as we know that market shares are negatively linked to alternative wages, then one run the risk to obtain negative signs on $\beta$. We try to correct for that revealed endogeneity however, by running General Methods of Moments (GMM) estimation methods.

\section{$5 \quad$ Econometric results}

Regressions are ran by industry. We preferred an industry-type specification instead of a country-type specification because from the point of view of industrial economics, market structures should be much more industryspecific than country specific in the OECD (see for instance the introduction chapter in Sutton (1991)). However, we account for permanent country heterogeneity as we perform fixed effect type estimations.

We deal with unbalanced panel data. We follow Davis (2002) and Wansbeck and Kapteyn (1989) who set-up a method of within-type transformation which produces two way fixed effects estimators consistent with incomplete panels. We shall call this method WKD in what follows ${ }^{7}$. The

7 Davis generalizes actually Wansbeek and Kapteyn's method to three-way, four or higher order error components. 
basic intuition is that the estimator of such a transformation is similar to that obtained by adding a dummy exogenous variable to the set of regressors for each missing observation. Practically however, it is far better to use their method of transformation than to add a big number of dummies that would have lead otherwise to impractical computation. Following Davis (2002), and considering matrix notation, the two way fixed effects in an unbalanced panel can be written: $Y=X \beta+\Delta_{i} \mu_{i}+\Delta_{t} \mu_{t}+u$ where $\beta$, $\mu_{i}$ and $\mu_{t}$ are parameters in the fixed effects model ${ }^{8}$. Assuming $\mathrm{N}$ the total number of observations, $N_{i}$ and $N_{t}$ denoting the number of observed individuals and time periods for which data is available, then $\Delta_{i}$ and $\Delta_{t}$ are two $\left(N * N_{s}\right)$ matrices, $s=i, t$, that represent respectively the set of indicator variables denoting observations on individuals $(i)$ and time periods $(t)$. Davis shows that the above model could be transformed into a within-type relation: $Q . Y=Q . X \beta+Q . u$, with $Q=Q 1-P 2, Q 1=I-\Delta_{t} *\left[\left(\Delta_{t}^{\prime}\right) * \Delta \mathrm{t}\right]^{-} *\left(\Delta \mathrm{t}^{\prime}\right)$ and $P 2=Q 1 * \Delta_{i} *\left[\left(\Delta_{i}^{\prime}\right) * Q 1 * \Delta_{i}\right]^{-} *\left(\Delta_{i}\right) * Q 1$. In what follows, all our regressions shall be based on this within transformation. We also ran GMM regressions based on these transformed variables with instruments transformed in the same manner.

We therefore provide WKD type estimates in the tables of results hereafter and when necessary General Methods of Moments (GMM), after testing for exogeneity of explanatory variables as well as instruments, by running systematically Durbin-Wu-Hausman and Over-identification tests". When the p-value relative to DWH test exceeds 0.05 , we do not reject the hypothesis that the explanatory variables are exogenous to the model and choose the Within model. However, when the DWH p-value is lower than 0.05 , we choose the GMM model and present estimates where the chosen instruments are orthogonal to the residual allowing the equation to be overidentified (see p-values from over-identification test results). The instruments used are mean national Wage at $(\mathrm{t}-2)$ and $(\mathrm{t}-3)$ (i.e. lagged twice or three times), labour Productivity (t-2) and (t-3), Market Shares in Domestic, Developing and Industrialized markets at $(\mathrm{t}-2)$ and $(\mathrm{t}-3)$.

Table 2 reports the results. First, as it is expected, the industry average wage and the productivity differential variables have significant positive effects on real industry wage per employee in most if not all of the industries.

The programs of variables transformation have been constructed using the matrix language (IML module) in SAS, and are available from the authors. We follow the method of Davis that appears to be more flexible and more general than that of Wansbeek and Kapteyn.

9 see Davidson and Mac Kinnon, 1994 for more detalls on these tests. 


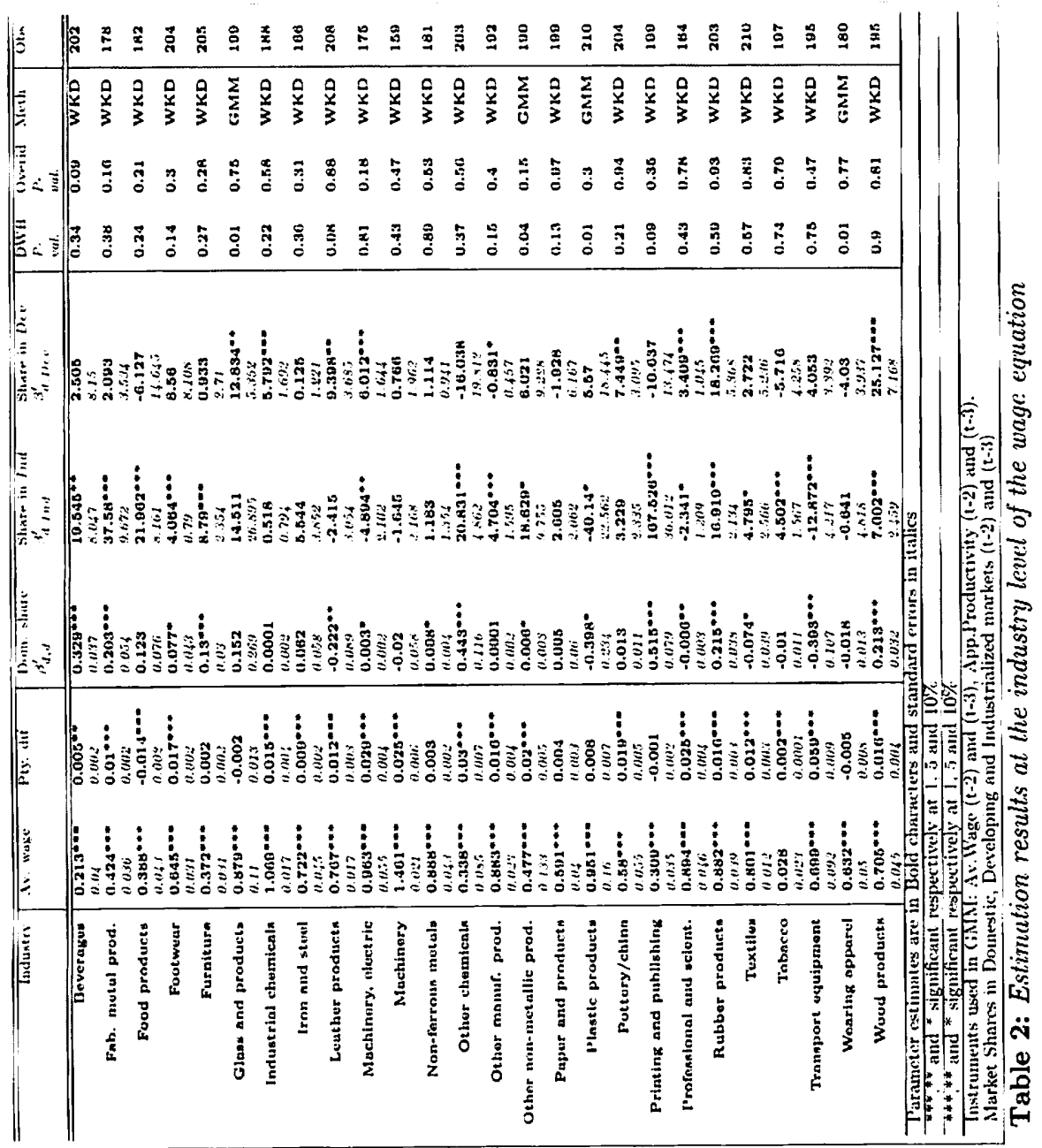


The second important observation is that the $\beta$ coefficients on foreign market share variables (in absolute terms), appear to be systematically higher than those on domestic market shares for all of the industries. Following our theoretical analysis, this result is consistent with spatial differentiation within the two groups of foreign destinations. For most of the exporting countries, the market that counts constitute a small part of those observed markets. Put differently, perceived demand laced by a typical exporter is much smaller due to spacial differentiation, which ends up increasing significantly the estimated parameter. Nevertheless, the parameters relative to domestic shares $\beta_{d}$, are mainly between 0 (non significant) and 0.5 , which is consistent with our theory when the market is much smaller and thus much more integrated in space.

The third observation we can make from table 2 is that in 13 out of these 26 industries, rents are acquired from exporting to developed markets (i.e. $\beta_{d, I n d}$ are positive and statistically significant in 13 industries). However, only 11 industries (around $40 \%$ ) benefit from the same outcome when selling to the domestic market. Within the OECD, outside markets appear then to be more profitable to exporters and their employees than domestic markets are.

The evidence of an extraction and distribution of rents is more limited when selling to developing markets (in 8 industries, $\beta_{d, D e v}>0$ and is statistically significant). It is interesting to note here, that the corresponding positive impact on wages prevails in industries where the market power of rich countries' producers is potentially large (chemicals or scientific and professional equipment for instance). On the opposite, the insignificant impact appears in industries usually known to be very competitive in developing markets (e.g. footwear or furniture). It remains however, that in the majority of the industries (18), selling to a developing market is not related to wage premiums.

Notice further that in some small minority of cases, $\beta$ coefficients appear to be negative and significant. In 3 cases (plastic products, professional and scientific prod. and transport provide examples), the negative sign appears on domestic and industrialized market shares. As explained earlier, this is inconsistent with our set-up for 2 possible reasons: either our theoretical relation does not fit well what is really going on in these sectors or, our data is not good enough to capture alternative wages. We think, however, that the second argument is what is producing these negative signs. As a matter of fact, if alternative wage proxies (average wages and productivity) do not well capture true alternative (market) wages, then the dependant wage variable could still contain some alternative wage variability. This results in an endogeneity between wages and market shares which bias downward the beta parameters. We try to account for these endogeneity problems by run- 
ning Instrumental variables or GMM regressions, but it seems that they do not perform very well for every considered industry. We leave these results aside in what follows, by solely concentrating on theory consistent results.

We have identified so far, the industries for which we estimate a positive relationship of rent sharing against those for which we do not. In what follows, we discuss the reasons for which we obscrve or not this relationship in light of the two tests that are presented in the prior section. Table 3 summarizes the results.

As it indicates, for 20 industries at least one channel of rent sharing is operating (at least one of the $\beta$ s is positive and statistically significant in those industries). This suggests that in nearly $77 \%$ of the OECD industries, unions exist and are strong enough to redistribute rents wherever they can be accuired. By applying the second test to discriminate between positive and no rents markets, one finds however that rents are mostly obtained from exporting to developed countries markets (i.e. 13 cases). The evidence is weaker when selling to the domestic and developing countries' markets (resp. 11 and 8 cases).

Nevertheless, there is a minority of industries where we do not observe channels of rent sharing. When the $\beta$ parameters are insignificant (Iron and Steel, Machinery, Paper and Prod., and Wearing Apparel), two factors can explain this outcome. First, no rents are acquired in all of the three markets. Second, rents might be acquired but unions are not strong enough to redistribute them over to employees.

\section{Robustness checks}

Most of the rent sharing studies are conducted on micro data levels, in general, where one can account for most of the determinants of the competitive wages (i.e. workers and/or firms' characteristics) and thus, be able to isolate rent sharing effects. However, as our study is based only on industry data, we run the risk of not isolating potential rent-sharing behavior through our $\beta$ estimates. We tend to show in this section however, that these parameters are really capturing what the theory wants them to, that is: the double existence of rents and unions in case $\beta>0$ or the absence of at least one of those for $\beta=0$. We cmphasize two sets of arguments related first, to the methodology undertaken and second, to the consistency of the $\beta$ parameters with empirical results and indexes found in the literature. 




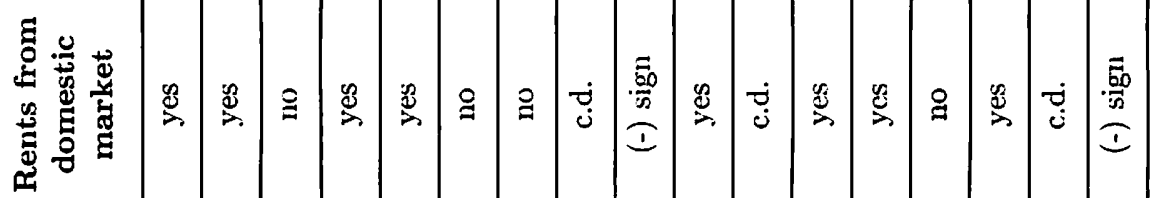

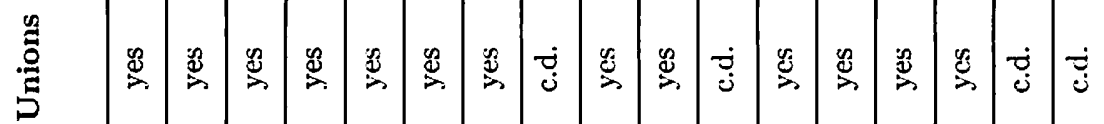

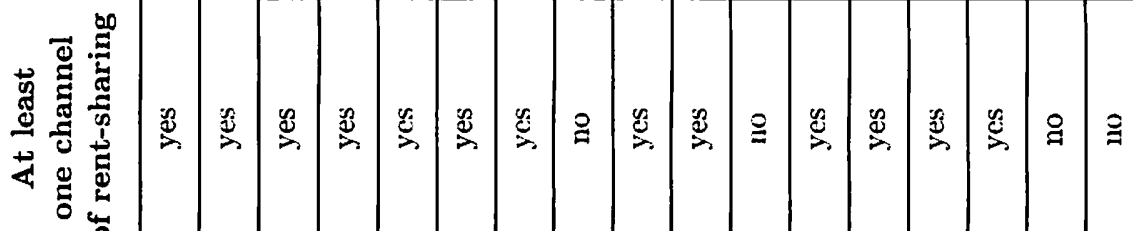

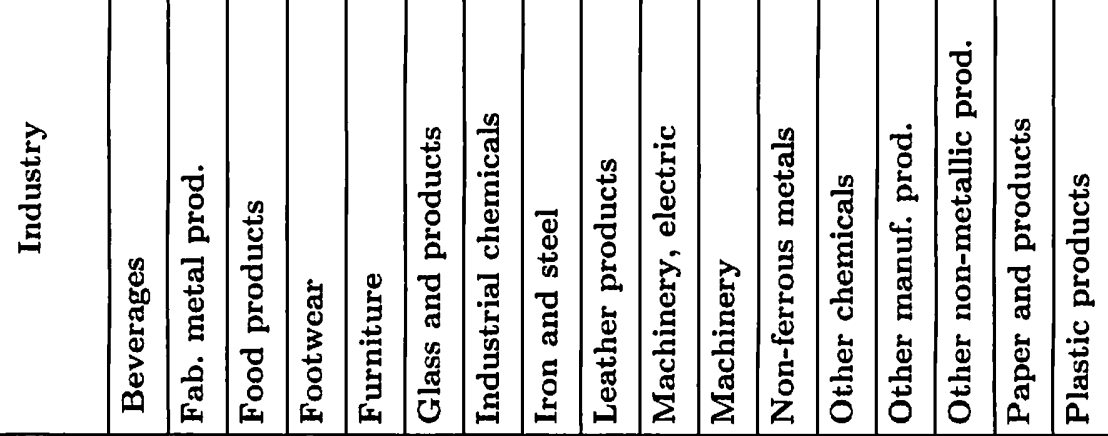




\begin{tabular}{|c|c|c|c|c|c|c|c|c|c|c|c|}
\hline 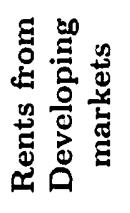 & 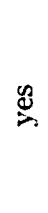 & $\supseteqq$ & 3 & $\stackrel{3}{3}$ & $\stackrel{\substack{x \\
2}}{2}$ & $\cong$ & $\cong$ & نَّ & $\stackrel{n}{2}$ & 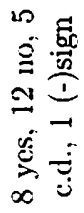 & \\
\hline 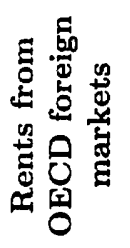 & $\cong$ & $\underset{\Sigma}{\Perp}$ & $\begin{array}{l}\frac{50}{6} \\
\frac{\sqrt{2}}{I}\end{array}$ & $\stackrel{\mathscr{D}}{\supset}$ & $\stackrel{E}{\mathscr{S}}$ & $\stackrel{3}{3}$ & $\frac{\sqrt{0}}{\mathrm{x}}$ & تُ & $\stackrel{8}{2}$ & 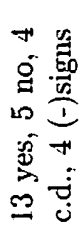 & \\
\hline 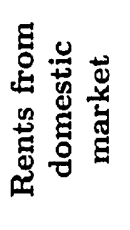 & 옴 & $\stackrel{\mathcal{Z}}{2}$ & $\frac{5}{\sqrt[5]{20}}$ & $\stackrel{\mathscr{D}}{\partial}$ & I & 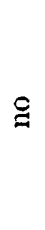 & 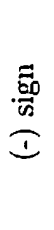 & نْ & $\stackrel{n}{3}$ & 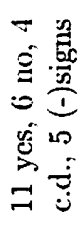 & 苨 \\
\hline פ & $\stackrel{\overbrace{}}{\partial}$ & 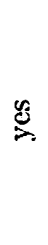 & $\stackrel{\mathscr{Z}}{2}$ & $\stackrel{\mathbb{E}}{2}$ & 2) & $\stackrel{3}{2}$ & نْ & نْ & $\stackrel{\text { f }}{\mathcal{f}}$ & 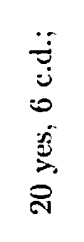 & 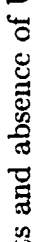 \\
\hline 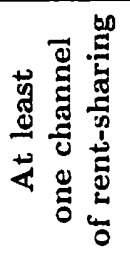 & $\stackrel{d}{0}$ & $\stackrel{\infty}{\bigotimes}$ & $\stackrel{3}{2}$ & $\stackrel{3}{2}$ & $\stackrel{2}{2}$ & 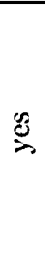 & $\cong$ & $\cong$ & $\stackrel{\infty}{2}$ &  & 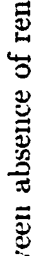 \\
\hline 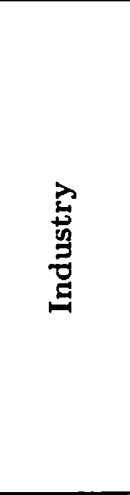 & 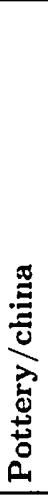 & 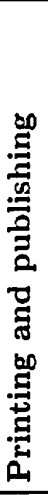 & 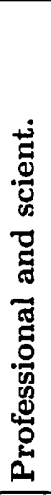 & 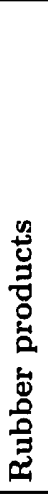 & 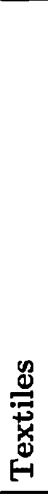 & 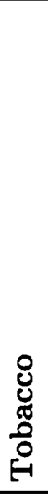 & 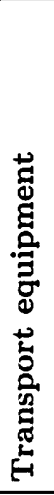 & 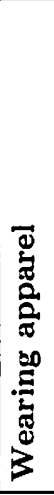 & 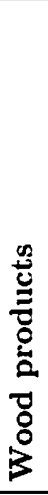 & 蔦 & 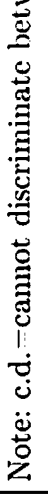 \\
\hline
\end{tabular}




\subsection{The methodology arguments}

1/ First, although usually the relation is expected to be negative between market shares and real wages, due to the fact that higher wages harm competitiveness ${ }^{10}$, we find a positive effect however in most of cases between these two variables. One of the few reasons that could explain this relation when productivity is already accounted for, is precisely the extraction and distribution of rents from selling to a particular market.

2 / Our theoretical framework reveals that the $\beta$ parameters relative to each market should be correlated. To see this, let us re-express the parameter $\beta$ for each market $j(\forall j \in\{d, I n d, D e v\})$ as:

$$
\beta_{d j}=[\overbrace{\lambda_{d l}}^{\text {unions' power }} \underbrace{\psi_{j j} \frac{\kappa_{i j}}{\sigma_{j}^{e}}}_{\text {firms' }}]=\lambda_{d l} \zeta_{j}
$$

where $\zeta_{j}=\psi_{i j} \frac{\kappa_{i j}}{\sigma_{j}^{e}}$. First, by assuming market structures to be similar across markets $\left(\zeta_{d}=\zeta_{\text {Ind }}=\zeta_{D e v}\right)$, one can easily deduce from the above relation that $\beta_{d d}$ should be positively related to the two others $\beta_{d, I n d}$ and $\beta_{d, D e v}$, as they all contain $\lambda_{d}$. Indeed, table 4 shows a very high and positive correlation between $\beta_{d d}$ and $\beta_{d, \text { Ind }}$ estimators across industries $(\mathrm{r}=0.70)$. However, the correlation appears to be negative but low between the developing market parameter $\beta_{t, D e v}$ and the rest. These results suggest that market structures are similar across developed countries (i.e: $\zeta_{d d}$ similar to $\zeta_{d, I n d}$ ), while they seem to be different between developed and developing markets.

3 / Our methodology provides a third reason for which our parameters are indeed informing about the theoretical story we tell. Appendix A shows how we properly aggregate the wage relation from the firm level to the industry level in order to be able to test it. The corresponding theoretical parameters turn out to contain the same information on market imperfections and power of unions than that obtained from the theoretical firm relation.

\subsection{Further investigating the beta parameters}

1/ We had access to 1990 OECD data on unions density and union coverage as two alternative indicators of unions' power (respectively identified by $\lambda_{d}^{d}$

${ }^{10}$ Recall that this could be due to the fact that contracts between unions and employers are not efficient, or the result of other wage setting policies (minimum wages, etc ...). 
and $\left.\lambda_{d}^{c}\right)$. Union density expresses the percentage of workers belonging to trade unions while union coverage indicator represents the percentage of workers who are covered by collective agreement. These data are country specific. Then, we have constructed new variables where now, market shares interact with one of these indicators that is supposed to roughly represent our $\lambda_{d}$ parameter. This enables us to run an alternative regression for wages where only the parameters $\zeta$ are now to be estimated (i.e. $\zeta$ represent market power on the commodity markets). We estimate two alternative equations where $1 / \lambda_{d}=\lambda_{d}^{d}$ and $2 / \lambda_{d}=\lambda_{d}^{c}$. These regressions are based on the following equation:

$$
\begin{aligned}
& \frac{w_{i t}}{\widetilde{p_{i t}}}=\zeta_{d}\left[\lambda_{d} *(E . S)_{d}\right]_{i t}+\zeta_{I n d}\left[\lambda_{d} *(E . S)_{I n d}\right]_{i t}+\zeta_{D e v}\left[\lambda_{d} *(E . S)_{D e v}\right]_{i t} \\
& +\beta_{w} \frac{\overline{w_{i t}}}{\widetilde{p_{i l}}}+\beta_{p t y} \frac{\left[P t y_{i t}-\overline{P t y_{i t}}\right]}{\widetilde{p_{i t}}}+\varphi_{i}+\varphi_{t}+u_{i t}
\end{aligned}
$$

The regressions are run using WKD or GMM methods where necessary. The resulted $\zeta$ estimators are then compared to the $\beta$ estimators obtained in the prior section. In fact, our theory suggests that when the $\beta$ parameter is positive and statistically significant, $\zeta$ has to have the same sign and be statistically significant as well (see $\beta_{d j}$ expression above). Table 4 provides another evidence related to the relevance of our $\beta_{d j}$ parameters estimated so far. Indeed, the sign and significance of the $\beta$ estimators appear to be very correlated with that of their direct correspondent $\zeta_{j}$ coefficients when using either of the unions' power indicators (between 0.73 and 0.85 when applying the $\lambda_{d}^{d}$ indicator; between 0.49 and 0.67 when using $\left.\lambda_{d}^{c}\right)$ " . The cross-correlation is also positive and relatively high between the parameters relative to the Industrialized markets and those of domestic markets ( 0.41 using $\lambda_{d}^{d}$ and 0.37 using $\lambda_{d}^{c}$ ). This is another evidence for similarity of market structures across developed countries' markets.

11 The correlation degree of 'signs and significance' is obtained by constructing a qualitative variable for each of the estimators $\zeta$ and $\beta, \forall$, that takes on 1 when the parameters are positive and statistically significant, 0 when they are insignificant and -1 when they appear to be negative (few values of -1 ). 


\begin{tabular}{|c|c|c|c|c|c|c|}
\hline Variable & $\boldsymbol{\beta}_{\text {Dom }}$ & $\boldsymbol{\beta}_{\text {Ind }}$ & $\boldsymbol{\beta}_{\text {Dev }}$ & $\operatorname{sign}_{\beta_{\text {Dom }}}$ & $\operatorname{sign}_{\boldsymbol{\beta}_{\text {Ind }}}$ & $\operatorname{sign}_{\boldsymbol{\beta}_{\text {Dev }}}$ \\
\hline$\beta_{\text {Dom }}$ & 1 & & & & & \\
\hline$\beta_{\text {ludl }}$ & 0.70 & 1 & & & & \\
\hline$\beta_{\mathrm{Dev}}$ & -0.03 & $\overline{-}$ & 1 & & & \\
\hline \multicolumn{7}{|l|}{ Using $\lambda^{d}$} \\
\hline $\operatorname{sign} \zeta_{\mid D_{\text {tun }}}^{d}$ & & & & 0.76 & 0.41 & 0.11 \\
\hline $\operatorname{sign} \zeta_{l_{1, u l}}^{1}$ & & & & & 0.85 & -0.19 \\
\hline $\operatorname{sign} \zeta_{D e v}^{d}$ & & & & & & 0.73 \\
\hline \multicolumn{7}{|l|}{ Using $\lambda^{c}$} \\
\hline $\operatorname{sign} \zeta_{\text {Dom }}^{d}$ & & & & 0.67 & 0.37 & 0.01 \\
\hline $\operatorname{sign} \zeta_{\text {lud }}^{d}$ & & & & & 0.63 & -0.18 \\
\hline $\operatorname{sign} \zeta_{D e v}^{d}$ & & & & & & 0.49 \\
\hline
\end{tabular}

Table 4: Correlation between $\beta, \zeta$ and OMSP estimators

2/ The value of the $\beta_{d}$ parameters relative to domestic shares are mainly between 0 (non significant) and 0.5 , which is consistent with our theory as well as other studies that try to evaluate properly the unions' market power parameter $\lambda_{d}$. In fact, Abowd and Lemicux (1993) and Abowd and Allain (1996)) evaluated the 'revenue shifter' $\lambda_{d}$ to be around 0.25 and 0.40 on average. As it is not a strong assumption to consider an hypothesis of perfect integration for the domestic market, $\kappa_{d}$ is then expected to be near or a little above unity. Meanwhile, given that $0<\psi_{d}<1$ and for values of elasticity of demand $\sigma$ around or above unity (See Goldstein and Khan (1985) or Erkel and Mirza (2002)), the ratio $\frac{\Psi_{d}}{\sigma_{d}}$ should be smaller than unity. This is perfectly consistent with our results on $\beta_{d}$.

All these evidence seem to support that our estimators are revealing some information about market power of firms and unions. They are consistent with our theoretical story of rents acquired and shared from exporting as long as firms have some market power and unions have sufficient bargaining power to shift them to employees.

\section{Conclusion}

This paper has focused on rent sharing issucs consecutive to openness. We have asked whether openness, through exporting, is a source of rents for an industry that are shared between its workers and capital holders. In partic- 
ular, we have asked whether export markets are as profitable as domestic markets for OECD exporters and their cmployees.

We have derived then tested a theoretical equation, based on rent sharing theories, linking industry wages to openness variables. This relationship has enabled to conduct a double discriminating test to identify the market sources of rents acquired for OECD industries, and whether or not these are shared with employees.

We have used industrial trade and activity data from two UNIDO databases on 22 OECD countries to test this equation. We have found that an increase of market shares in at least one of the destination markets is associated with an increase in wages, in nearly four fifth of the industries. This indicates that in a high majority of the OECD industries unions exist and do shift rents from wherever they are extracted. We have also found however, that in most of the cases, those rents that are shared are more acquired from exporting to other rich countries than from selling to the domestic or the less developed countries' markets.

\section{References}

Abowd, J. (1989). "The Effect of Wage Bargains on the Stock Market Value of the Firm". American Economic Review 79 (4).

Abowd, J. and L. Allain (1996). "Compensation Structure and Product Market Competition". NBER. Working Paper March.

Abowd, J. and T. Lemieux (1993, November). "The Effects of Product Market Competition on Collective Bargaining Agreements: The Case of Forcign Competition in Canada". Quarterly Journal of Economics 108 (4), 983-1014.

Borjas, G. and V. Ramey (1995, December). "Foreign Competition, Market Power, and Wage Inequality". Quarterly Journal of Economics 110 (4), 1075-1110.

Brander, J. and P. Krugman (1983). "A 'Reciprocal Dumping' Model of International Trade". Journal of International Economics 15, 313-321.

Brock, H. and S. Dobbelaere (2006). "Has International Trade Affected Workers Bargaining Power?". Review of World Economics Forthcoming.

Brown, J. and O. Ashenfelter (1986). "Testing The Eÿciency of Employment Contracts". Journal of Political Economy 94 (3), S55-S78.

Budd, J., J. Konings, and M. Slaughter (2005). "International Profit Sharing in Multinational Firms". Review of Economics and Statistics 87(1), 73-84.

Budd, J. and M. Slaughter (2004). "Are Profits Shared Across Borders? Evidence on International Rent Sharing". Journal of Labor Economics 22 (3), 525-552. 
Card, D. (1990). Unexpected Inflation, Real Wages, and Employment Determination in Union Contracts. American Economic Review $L X X X, 669-688$.

Christofides, L. N. and A. Oswald (1991). Eÿcient and Ineÿcient Employment Outcomes: A Study Based on Canadian Contract Data. Research in Labour Econmics XII, 173-190.

Davis, P. (2002). "Estimating MultiWay Error Components Models with Unbalanced Data Structures". Journal of Econometrics 106, 67-95.

Erkel-Rousse, H. and D. Mirza (2002). Import Price-Elasticity: Reconsidering the Evidence. The Canadian Journal of Economics 2: 282-306.

Geroski, P. (1983). "Some Reflexions On The Theory And Application of Concentration Indices". Journal of Industrial Economics 1, 79-94.

Geroski, P. (1998). "Thinking Creativcly About Markets". International Journal of Industrial Organization 16 (2), 677--695.

Goldstein, M. and M. Khan (1985). "Income and Price Effects in Foreign Trade". In Handbook of International Economics (North Holland ed.), Volume 2. Ed. by R.W Jones and P.B. Kenen.

Hosken, D. and D. Margolis (1997). The Eÿciency of Collective Bargaining in Public Schools. CREST-INSEE Working Paper. N 9755.

Martin, S. (1993). Advanced Industrial Economics. Blackwell.

Oliveira Martins, Y., S. Scarpetta, and D. Pilat (1996). Mark-up in manufacturing industries: estimates for 14 oecd countries. OECD working paper n.162.

Schmalensee, R. (1989). "Inter Industry Studies of Structure and Performance" (North Holland ed.), Volume 2, pp. 951-1009. Handbook of Industrial Economics, ed. by R. Shmalensee and R.D. Willig.

Sen, A. and A. Dutt (1995). "Wage Bargaining, Imperfect Competition and the Markup: Optimizing Microfoundations". Economics Letters 48 (1), 15-20.

Sutton, J. (1991). Sunk Costs and Market Structure: price competition, advertising and the evolution of concentration. The MIT press.

Wansbeek, A. and A. Kapteyn (1989). "Estimation of the Error-Component Model With Incomplete Panels". Journal of Econometrics, 341-361. 


\section{A Aggregation strategy to industry level}

How can we obtain a wage relation at the industry level (equation 6 in the text) from the firm level equation 5 (in the text)? 2/ How can weighted market shares and wages be related at the industry level?

Before manipulating the wage equation, an aggregation of the markups from the firm to the industry level is necessary to understand our story. Reconsider the mark-up expression on one market, say the foreign market (that of domestic market will be deduced in the same manner). Here we proceed as in most industrial organization textbooks to obtain average markups at the industry level from firm level mark-ups (sce Martin (1993)). Thus, weight the export mark-up equation 4 for a firm by its market share relative to all other firms from the same nationality $\left(x_{f n} / X_{d f}\right)$, and sum over all $N_{d}$ firms exporting from $d$ to market $f$. We have:

$$
\begin{aligned}
\sum_{N_{d}}\left[\frac{x_{f i}}{X_{d f f}}\right] \frac{p_{f}^{-w_{u}}}{p_{f}} & =\frac{p_{f} X_{d f}-w_{u} X_{d f}}{p_{f} X_{d f}} \\
& =\frac{1}{\sigma_{f}} \sum_{N_{d}} \frac{x_{f n}^{2}}{X_{d f}} \frac{1}{X_{f f}} \\
& =\frac{1}{\sigma_{f}} \sum_{v_{d}}\left[\frac{x_{f, n}}{X_{d f}}\right]^{2} \frac{X_{d f}}{X_{f f}} \\
& =\frac{1}{\sigma_{f}} \psi_{f} S_{f}
\end{aligned}
$$

with $\psi_{f}=\left[\frac{x_{f n}}{X_{d f}}\right]^{2}$

As noticed, industry mark-up to exports (i.e. weighted average of firm mark ups) is now related to elasticity of demand $\left(\sigma_{f}\right)$, a concentration index that informs about the degree of competition within all the firms of the same nationality selling to the foreign market $f$ (i.e. $\psi_{f}$ ) and finally, total market share of these firms on the foreign market.

How do the industrial wage rate per employee and industry mark-ups interact? To see this, multiply the wage rate $\left(w_{n}\right)$ expression by $l_{n}$, and sum over the $N_{d}$ firms we have:

$$
\sum_{n=1 \ldots N_{d}} w_{n} l_{n}=b_{d} \sum_{n} p_{n} l_{n} \frac{p_{d d} x_{d n}}{p_{n} y_{n}} \frac{x_{d n}}{X_{d}}+b_{f} \sum_{n} p_{n n} l \frac{p_{f} x_{f n}}{p_{n} y_{n}} \frac{x_{f n}}{X_{f}}+w_{u} L
$$


recall that if $l_{n}=y_{n}$ then $L=\sum l_{n}=Y$. Then, by dividing the wage bill at the industry level by $L$ in order to obtain an expression for the industry wage per employee, we have:

$$
\begin{aligned}
w & ==\frac{\sum_{n=1 \ldots N} u_{n} l_{n}}{L} \\
& =p_{d d} \lambda \frac{1}{\sigma_{d}} \sum_{n} x_{d n}^{2} \frac{1}{X_{d d}} \frac{1}{Y}+p_{f} \lambda \frac{1}{\sigma_{f}} \sum_{n} x_{f n}^{2} \frac{1}{X_{. f}} \frac{1}{Y}+w_{1} \\
& =p_{d} \lambda \underbrace{\frac{1}{\sigma_{d}} \sum_{n}\left[\frac{x_{d n}}{X_{d d}}\right]^{2} \frac{X_{d d}}{X_{. l}}}_{\text {Industru uecragre markup on } d} \frac{X_{d d}}{Y}+p_{f} \lambda \underbrace{\frac{1}{\sigma_{f}} \sum_{n}\left[\frac{x_{f n}}{X_{d f}}\right]^{2} \frac{X_{d f}}{X_{. f}}}_{\text {lndustry anc rage markup on } f} \frac{X_{d f}}{Y}+w_{u}
\end{aligned}
$$

From this expression we can already see the relation between industry average wage rate and industry average mark-ups. Recall from the text $S_{d}=X_{d d} / X_{d}$ and $S_{f}=X_{d f} / X_{. f}$ to be the market shares held on the domestic and foreign markets for a given industry. Recall $E_{d}$ and $E_{f}$ to be the corresponding industrial rates of domestic sales and exports. Finally we have defined $\left[\Sigma n\left(\frac{x_{d, n}}{X_{d d}}\right)^{2}\right]$ (resp. $\left.\psi_{f}\right)$ to be a concentration index that informs about the degree of competition within all the firms of the observed country selling to its market $d$ (resp. to market $f$ ). We can now derive the industry relation of real average wages from above :

$$
\begin{aligned}
\frac{w}{p} & =b_{d d}^{\prime} \frac{X_{d d}}{X_{d d}} \frac{p_{d} X_{d d}}{p Y}+b_{d f}^{\prime} \frac{X_{d f} p \frac{X_{d f}}{X_{f}}+w_{u}}{p Y}+w \\
& =b_{d k{ }_{d d}^{\prime} S_{d} E_{d}+b_{d f}^{\prime} S E_{f}+w_{u}}^{\text {where }} \\
b_{d d}^{\prime} & =\frac{\lambda \Psi_{d}}{\sigma_{d}}
\end{aligned}
$$

and

$b_{d f^{\prime}}=\frac{\lambda \psi_{f}}{\sigma_{f}}$

One can now understand why weighted market shares are key regressors. In fact, an increase in a weighted market share held in one market will lead to an increase in the average markup of that industry as far as the market is imperfectly competitive (i.e the value of $\sigma$ is not so high and that of $\psi$ not too small). Whether or not this affects positively wages in return depends then on the bargaining power of the unions through $\lambda$. This is precisely the relation that is estimated in the text (See the interpretation in more details in the text). 


\section{B Generalization of the theory}

We generalize our 2 country case to $J$ countries' model. The corresponding markets are assumed to be internationally segmented. Note that $j$ can be the domestic market $(j=i)$ or the foreign market $(j \neq i)$, so that each time that the firm serves the domestic market we shall say that it 'exports' to this market.

The objective function to maximize would be

$\left(l_{i, n}\left[w_{i, n}-w_{u, j}\right]\right)_{i}^{\dot{x}_{i}}\left[\left(\sum_{j=1}^{J} p_{i j, n} x_{i j, n}\right)-w_{i, n} l_{i, n}\right]^{1-\lambda_{i}}$

From the first order conditions we derive the following wage equation:

$w_{i, n}=\lambda_{i}\left(\frac{\sum_{j} p_{i j, n} x_{i j, n}-w_{u, i} l_{i, n}}{l_{i, n}}\right)+w_{u, i}$

Besides, equating marginal revenue to marginal cost in each market, and considering equation 11 we derive the following quasi mark-up equation on each export market $j$ :

$$
\frac{p_{i j, n}-w_{u, i}}{p_{i j, n}}=\frac{1}{\sigma_{j}} s_{i j, n}
$$

Equation 12 is closely related to the Structure-Conduct-Performance type expressions in a Cournot game, since 'quasi' mark-ups depend on price-elasticity of demand $\sigma$ and the market share $s_{i, j, n}=x_{i, j, n} X_{j}$, with $X_{j}$ representing total sales in the market $j^{12}$.

For ease of exposition, we assume that output equals labor demand $y_{i n}=\sum_{j=1 \ldots J} x_{i j, n}=l_{i, n}$. Let $p_{i, n} y_{i, n}=\sum_{j} p_{i j, n} x_{i j, n}$ be the total revenue for firm $n$ and $b_{i j}=\left(\lambda_{i} \frac{1}{\sigma_{j}}\right), \forall j \in 1 \ldots J$. Expressing by $j$ ' a foreign market different from the domestic one $i$, then equations 11 and 12 give the following real wage function that generalizes equation 2 for the case of $J$ markets:

$$
\frac{w_{i, n}}{p_{i, n}}=b_{i i} e_{i i, n} s_{i i, n}+\sum_{j^{\prime} \neq i}\left[b_{i, j^{\prime}} e_{i j^{\prime}, n} s_{i j^{\prime}, n}\right]+\frac{w_{n, i}}{p_{i, n}}
$$

12 One could easily extend the Cournot case to a more general case of conjectural variations. Such an extension leads to the same type of equations to test however, except that the coefficients is to be inferred would then contain a conjectural variation parameter that reveals the form of the firms' behavior. 
where, $e_{i j, n}=\left(\frac{p_{i j} x_{i j, n}}{p_{i, n} y_{i, n}}\right)$ stands for the export rate of firm $n$ in the market $j$. Then, the real wage equation, net from the real alternative wage, is a linear combination of the sum of export market shares weighted by the export rate to each country $j$. This expression extends simply to the industrial level (see appendix above) to give:

$\frac{w_{i}}{p_{i}}=b_{i i}^{\prime} E_{i i} S_{i i}+\sum_{j^{\prime} \neq i} b_{i j}^{\prime}, E_{i j}, S_{i j}+\frac{w_{u, i}}{p_{i}}$

where the $b^{\prime}$ arc expressed again as in the appendix above.

\section{Robustness of the Specified Equation to differentiation}

We follow Gerosky's (1983) specification in the presence of product differcntiation. Goods are differentiated because each good is assumed to have its specific market. Put differently, every variety is unique as it is only partially comparable to the others ${ }^{13}$. However, goods could also be geographically differentiated. For instance, in a big region $j$, where local markets are distant from one another, demand addressed to a firm in a market, say $m_{1}$, could have little if any effect on the perceived demand of other firms selling in another marketplace, $m_{2}$. On the opposite, if markets $\mathrm{m} 1$ and $\mathrm{m} 2$ are very close, and thus, tend to be integrated into one overall market $j$, then consumers' total demand perceived by each firm in this region $j$ tends to match total supply from these firms.

Hence, let $X_{j, n_{i}}^{e}=x_{i j, n}+\theta_{i}\left[\sum_{n^{\prime} \neq n,} x_{i j, n^{\prime}}+\sum_{i^{\prime} \neq i} X_{i^{\prime} j}\right]$ be the total 'effective' demand faced by firm $n$. The parameter $\theta_{j}$ can be considered either an indicator of product or spatial differentiation or a combination of both. The value of $\theta_{j}$ varies between 0 (perfectly differentiated good or geographically segmented markets) and 1 (perfectly homogeneous good or perfectly integrated markets within $j$ ). Then, the Lerner index for firm $n$ is determined by the same function of that expressed for the homogeneous good and perfectly integrated market equation 11 , except that price-elasticity $\sigma_{i j, n}^{e}$, and the firm $n$ 's market share $s_{i j, n}^{e}$ are defined in terms of 'effective' quantities. Recalling the mark up equation we then have:

$\frac{p_{i j, n}-w_{u, i}}{p_{i j, n}}=\left[1 / \sigma_{i j, n}^{e}\right] * s_{i j, n}^{e}$

${ }^{13}$ see also Gersoky (1998) who defines the market in 'strategic' terms. The main idea is that managers think about conceiving a product that creates its own market. 
with $s_{i j, n}^{\mathrm{c}}=\frac{x_{i j, n}}{X_{j}} \frac{X_{j}}{X_{j, n_{i}}^{\mathfrak{c}}}=s_{i j, n} \frac{X_{i}}{X_{j, n_{i}}^{\mathfrak{c}}}$ representing the effective share of firm $n$ on region $j$. Notice that 'effective' or 'perceived' market share is systematically higher than observed market share $\frac{x_{i j, n}}{X_{j}}$ which results in higher firms' rents at equilibrium. Following Martin's (1993) specification, let $\sigma_{i j, n}^{e}=\sigma_{j}^{e}$, $\sigma_{i j, n}^{e}=\sigma_{j}^{e^{\prime}}$. Note $\kappa_{i j, n}=\frac{X_{j}}{X_{j, n_{i}}^{e}}$. This parameter equals 1 when goods are perfectly homogeneous (resp. perfectly integrated region): and reaches $\left(\frac{X_{j}}{x_{i j, n}}\right)$, $\forall j \in\{i, j\}$ when the variety that is produced by firm $n$ is perfectly differentiated (resp. perfect market segmentation), (i.e: $\theta_{j}=0$ ). Then equation 13 becomes:

$$
\frac{w_{i, n}}{p_{i, n}}=\lambda_{i}\left(\frac{\kappa_{i i, n}}{\sigma_{i}^{e}}\right) e_{i i} s_{i, n}+\lambda_{i} \sum_{j}\left[\left(\frac{\kappa_{i j, n}}{\sigma_{j}^{e}}\right) e_{i j} s_{i, j, n}\right]+\frac{w_{u, i}}{\mu_{i, n}}
$$

We add the assumption that firms are sufficiently small in each market $j$. In that case, the value of $\left[\theta_{j} \sum_{n^{\prime \neq n} .} x_{i j, n^{\prime}}+\theta_{j} \sum_{i^{\prime} \neq i} X_{i^{\prime} j}\right]$ is sufficiently large, which enables us to consider that $X_{j, n_{i}}^{e} \approx X_{j, n_{i}^{\prime}}^{e}, \forall n, n^{\prime} \in i$. Hence, $\kappa_{i j, n} \approx \kappa_{i j, n^{\prime}} \approx \kappa_{i j}$; $\forall n, n^{\prime} \in i$. Aggregating at the industry level leads to the following average real wage equation:

$$
\frac{w_{i}}{p_{i}}=\beta_{i i} E_{i i} S_{i i}+\sum_{j \neq i} \beta_{i j} E_{i j} S_{i j}+\frac{w_{u, i}}{p_{i}}
$$

where

$$
\beta_{i i}=\left\lceil\lambda_{i} \psi_{i} \frac{\kappa_{i i}}{\sigma_{i}^{e}}\right\rceil
$$

and $\forall j \neq i$

$$
\beta_{i j^{\prime}}=\left[\lambda_{i} \psi_{i j^{\prime}} \frac{\kappa_{i j^{\prime}}^{e}}{\sigma_{j^{\prime}}^{e}}\right]
$$

By considering three markets $j$; with $j \in\{d, I n d, D e v\}$, replacing the real price by its estimate and the alternative wage by its function (eq. 7 ) in the wage relation 17 , that relation corresponds then exactly to the equation 8 we have chosen to estimate. 